\title{
A desconstrução de argumentos: uma análise de comentários online
}

Beatriz Pacheco

Mestre em Letras, UFRJ. Docente no Curso de Jornalismo, UBM.

Alexandra Mansur

Pós Graduada em Letras, UGB. Docente no Colégio Interativo, Volta

Redonda. 


\section{Resumo}

Usar a sofisticação da palavra foi uma condição para que o homem saísse de uma situação primitiva em que se usava a força bruta nas suas conquistas para uma situação moderna em que as conquistas se dão a partir da persuasão. Persuadir, por meio de estratégias de raciocínio, é um recurso não somente requintado, como também imprescindível ao processo civilizatório. A argumentação está atrelada à vida em sociedade que sofreu um forte impacto no último século, na medida em que tecnologias digitais ocuparam um lugar estratégico no desenvolvimento social e proporcionaram novas formas de sociabilidade e novas possibilidades de comunicação e interação. Além de transformar nossa maneira de pensar e entender o mundo, a web 2.0 revolucionou a argumentação, uma vez que proporciona ao indivíduo a experiência singular de olhar para o mesmo objeto sob perspectivas múltiplas. Este trabalho visa analisar as estratégias utilizadas nas crônicas argumentativas e nos comentários associados a essas crônicas, no Jornal Folha de São Paulo online. O estudo da formulação de argumentos voltados para a persuasão no meio digital permite analisar os diferentes pontos de vista dos leitores e de que forma o diálogo do autor com o leitor é entremeado por opiniões convergentes e/ou antagônicas. Para cumprir essa tarefa, seguimos os modelos argumentativos, delineados, principalmente, por Othon M. Garcia na obra Comunicação em Prosa Moderna.

Palavras-chave: comentários - argumentação - persuasão

\section{Abstract}

To use the sophistication of the word was a condition for men to emerge from a primitive situation in which the brute force was used in his conquests to a modern situation in which conquests are made by persuasion.Persuading, through reasoning strategies, is a resource not only exquisite, but also essential to the civilizing process. The argument is tied to life in society that has had a strong impact in the last century as digital technologies have occupied a strategic place in social development and have provided new forms of sociability and new possibilities for communication and interaction. In addition to transforming our way of thinking and understanding the world, web 2.0 has revolutionized argumentation since it provides the individual with the unique experience of looking at the same object under multiple perspectives. This paper aims to analyze the strategies used in the argumentative chronicles and the comments associated with these chronicles, in the Folha de São Paulo online newspaper. The study of the formulation of arguments for persuasion in the digital environment allows us to analyze the different points of view of readers and how the author's dialogue with the reader is interspersed with convergent and / or antagonistic opinions.To fulfill this task, we follow the argumentative models, outlined, mainly, by Othon M. Garcia in the work Communication in Modern Prose. 
Keywords: Comments - Argumentation - Persuasion

\section{Introdução}

A sociedade sempre foi dividida em grupos que têm interesses diferentes, essa é a razão de os discursos também serem espaço da contradição, ou melhor, da argumentação. A construção de uma sociedade democrática depende da convivência desses diversos interesses. Desse modo, é a argumentação que confere qualidade ao debate entre os discursos divergentes.

A chamada sociedade da informação oferece meios que viabilizam a interação entre distintos segmentos sociais: uma nova ordem foi estabelecida com a web 2.0. O sociólogo Manuel Castells (2003) enfatiza o poder que tem a sociedade em rede de revitalizar a democracia.

Raquel Recuero, em sua obra Redes Sociais na Internet (2009), aponta para as profundas mudanças nas formas de organização, identidade, conversação e mobilização social, procedentes da comunicação mediada pelo computador. Para a autora, a ampliação da capacidade de conexão permitiu que novas redes fossem criadas, as redes sociais digitais. Tais redes "conectam não apenas computadores, mas pessoas" (RECUERO, 2009, p.17) e estão presentes de forma numerosa no espaço virtual.

Um desses meios é a utilização pela própria imprensa de informação e comentários de seus usuários. Neste trabalho, foram analisadas as estratégias argumentativas utilizadas nas crônicas e nos comentários a elas associados, no Jornal Folha de São Paulo online. Como objetos de análise foram selecionados três artigos e comentários que acreditamos revelar a qualidade desse debate.

Quanto ao desenvolvimento do artigo, num primeiro momento, procedemos a uma revisão bibliográfica do trabalho do professor Othon M. Garcia em Comunicação em Prosa Moderna, livro editado em 1967 e até os dias de hoje um referencial no estudo sobre produção de texto. A partir daí, apresentamos as análises. 


\section{Fundamentação Teórica}

\section{ARGUMENTAÇÃO}

Os estudos sobre argumentação compõem um campo vasto, complexo e, inclusive, multidisciplinar, pois todo discurso tem uma dimensão argumentativa. Dessa forma, a matéria é do interesse de diversas áreas do conhecimento humano: o Direito, a Sociologia, a Filosofia e as Ciências da Linguagem, embora tenha alcançado o estatuto de objeto legítimo de investigação linguística.

Argumentar é necessário quando defendemos um ponto de vista e é a língua que nos permitirá fazer uma série de gradações argumentativas. $\mathrm{Na}$ oralidade e na escrita, é de fundamental importância dominar estes recursos.

Escrevemos/falamos sempre com alguma intenção: informar, persuadir, divertir, enfim, intervir no mundo. Bernardo (2000) chama nossa atenção para o fato de que, para persuadir, não necessitamos somente de leitura, mas de uma vontade genuína de transformar o mundo: "ler não é a condição para escrever, mas sim munição para viver, e para escrever também." (p.29). A leitura amplia nossa compreensão do mundo: quando nossa intenção é persuadir, necessitamos de informações que extrapolam o simples ato de convencer, visto que nossos discursos estão intimamente ligados a questões ideológicas que, muitas vezes, interferem em nossas vontades.

Um texto de opinião, como é parte de nosso objeto - uma crônica argumentativa -, não deve falar o que queremos ouvir, pois isso já dissemos, deve sim trazer o diferente, o contraponto e nos levar à dúvida. O outro "não precisa somente do seu espelho. Precisa, sim, muito de um reflexo - do reflexo inesperado que estabelece a diferença entre os diferentes" (BERNARDO, 2000, p. 34).

A fim de apresentar perspectivas diferentes e com clareza, devemos buscar ferramentas que assegurem minimamente um diálogo. Nesse sentido, buscamos dar ênfase ao trabalho de Othon Moacyr Garcia que é para a grande maioria dos teóricos uma referência.

Para o citado autor, necessitamos distinguir primeiramente dissertação e argumentação. $\mathrm{Na}$ dissertação, expomos o que sabemos ou acreditamos saber sobre 
determinado assunto e ainda externamos nossas opiniões. $\mathrm{Na}$ argumentação, além disso, "procuramos principalmente formar a opinião do leitor/ouvinte": "Argumentar é, em última análise, convencer ou tentar convencer mediante a apresentação de razões, em face da evidência das provas e à luz de um raciocínio coerente e consistente.” (p.381)

$\mathrm{O}$ que o autor caracteriza de argumentação nada tem a ver com bate-boca sem sentido ou com animosidade. Deve ser construtiva na sua finalidade, cooperativa e útil. São bases para a argumentação a consistência do raciocínio e a evidência das provas. São cinco os tipos de evidência: os fatos, os exemplos, as ilustrações, os dados estatísticos e o testemunho.

A argumentação informal está presente em tudo o que fazemos no nosso cotidiano e não seria diferente no nosso objeto de estudo, uma vez que há potencialidade de interação. Toda argumentação na essência é uma declaração seguida de provas. O autor ressalta que esta também corre o risco de ser falaciosa.

A estrutura típica da argumentação informal segue o seguinte esquema: proposição, seguida de concordância parcial, contestação e conclusão. Por proposição, entende-se que é uma declaração que deva ser atribuída a terceiros; a concordância parcial é quase (ou deveria ser) natural, pois toda tese deve ser olhada por dois lados; já a contestação é a oposição feita a argumentos precedentes e deve ter cuidado de ser mais consistente do que eles e, por fim, a conclusão, imprescindível a qualquer argumentação, deve resumir a questão posta.

Othon cita Whitaker Penteado (OTHON, 2010, p. 387) para elencar normas ou sugestões a fim de refutar argumentos: refute o argumento mais forte; ataque os pontos fracos da argumentação; utilize a técnica de redução às últimas consequências, veja se o opositor apresentou evidência adequada; escolha uma autoridade que tenha dito o contrário do seu opositor; aceite os fatos, mas demonstre que foram mal empregados; ataque a fonte; cite exemplos semelhantes que provem o contrário; demonstre que a citação do opositor foi deturpada e, por fim, analise os demais argumentos contrários e revele suas inconsistências.

A argumentação formal pouco difere em essência da informal, mas exige alguns cuidados. A proposição deve permitir divergência de opiniões, ou seja, deve ser argumentável. É necessária também a análise da proposição que não costuma aparecer na argumentação informal. A formulação dos argumentos é a apresentação de provas ou 
razões que sustentem a proposição. A conclusão não é simples recapitulação, consiste em pôr em termos claros, insofismáveis, a essência da proposição.

Sob a perspectiva de Othon M. Garcia, aprender a escrever é aprender a pensar. Aprender a encontrar ideias e conectá-las. Para isso, é necessário formar repertório. Pôr em ordem o pensamento e ter o que dizer é fundamental. A fim de discutir o que de fato é pensar, o autor relata alguns procedimentos de organização do pensamento: métodos ou processos de raciocínio.

O primeiro reflete sobre a validade das declarações. Toda declaração (ou juízo) só pode ser validada com fatos que a comprovem. Há, no entanto, declarações que independem de provas: quando expressa uma verdade universal, quando é evidente por si mesma, quando tem apoio de uma autoridade ou quando escapa ao domínio puramente intelectual.

É necessário também distinguir fato de indício. Indício nos permite apenas fazer inferência, não temos certeza, é uma possibilidade ou probabilidade: "o que se declara [...] é possível, é mesmo provável, mas não é certo porque é não provado" (p.303, op.cit) e "Indícios podem persuadir, mas não provam" (p.304, op.cit) Para que os fatos provem, é também necessário que "sua observação seja acurada, e que eles próprios sejam adequados, relevantes, típicos ou característicos, suficientes e fidedignos.” (304, op.cit)

Ao discutir a argumentação, o autor também ressalta o papel dos métodos, uma vez que método é o caminho por meio do qual se chega a um fim. Método implica um rumo seguido nas operações mentais:

"Distinguem-se primordialmente dois tipos de operações mentais na busca da verdade, vale dizer, dois métodos fundamentais de raciocínio: a indução (que vai do o particular para o geral) e a dedução (que parte do geral para o particular).” (p.306, op.cit)

$\mathrm{Na}$ indução, partimos da observação e análise dos fatos para chegar a uma conclusão, partimos do efeito para a causa: "É um raciocínio a posteriori” (p. 307, op.cit) que deve ser feito a partir de uma exaustiva investigação. Essa investigação pode ser substituída pelo testemunho autorizado, uma autoridade no assunto, pois um texto é construído também a partir de outros saberes.

Já na dedução, partimos do geral para o particular, da generalização para a especificação. "É método a priori: da causa para o efeito." (p.309, op.cit). A formalização do método é o silogismo: parte-se de duas premissas, uma maior e outra menor e chegase a uma conclusão. Silogismo é um raciocínio feito a partir de três proposições: uma 
premissa maior, universal; uma premissa menor, que mantém com a antecedente uma ideia comum, e uma conclusão, inferida pela união das duas primeiras proposições.

O silogismo pode ser válido e verdadeiro, mas pode também ser só uma coisa sem ser outra e, assim, não terá validade, pois a conclusão somente pode ser verdadeira, se as premissas o forem. Para Garcia, "Raramente chegamos à descoberta da verdade apenas por via indutiva ou apenas por via dedutiva: os dois métodos conjugam-se para o mesmo fim."(311, op.cit)

No trabalho do professor, também merecem destaque os argumentos falaciosos, que induzem ao erro. Entendemos por falácia ou sofisma todo raciocínio apressado, incompleto ou vicioso que pode ser intencional ou não. É importante estudá-lo por duas razões: uma, para perceber quando estão nos enganando com argumentos aparentemente sólidos; outra, para não cometermos o mesmo erro.

Garcia enumera alguns: falsos axiomas, ignorância da questão, petição de princípio, observação inexata, ignorância da causa ou falsa causa, erro de acidente, falsa analogia e probabilidade. Um axioma é uma proposição máxima geralmente aceita na ciência e na moral, um falso axioma é aquele que apenas tem aparência de verdade. Uma das falácias mais populares é a ignorância da questão, pois foge aos fatos, ao raciocínio frio e apela-se para emoção. A petição de princípio apresenta a própria declaração como prova dela. Em relação à observação inexata, por não se observar os fatos ou dados concretos, chega-se a conclusões ou a declarações incompletas. A ignorância da causa ou falsa causa pode nos levar a atribuir como verdadeira causa dos fatos o que é simples aparência ou coincidência. Para Garcia, é uma "maneira simplista de explicar os eventos, pois o que vem antes não é, necessariamente, a causa do que vem depois. (p.320, op.cit)". Temos também o que o autor denomina erro de acidente, pois se toma o acidental como um atributo essencial, o que resulta uma generalização falsa. $\mathrm{Na}$ falsa analogia ou probabilidade, há uma indução parcial ou imperfeita que conclui do particular para o particular.

\section{ANÁLISE DO CORPUS}

A primeira crônica, Meninas, de Fernanda Torres (Anexo 1), traz como ideia central a discussão de como a Aids reconfigurou o comportamento feminino no mundo. 
A autora afirma que a homossexualidade feminina foi não só disseminada, como também canonizada. Para defender esse ponto de vista, a articulista mobiliza o seguinte argumento: o contágio pelo vírus HIV não ocorreria nas relações sexuais entre mulheres. Dessa forma, apresenta seu argumento como verdade universal, mas não traz provas que sustentem sua proposição.

Mais adiante, defende a ideia de que o movimento \#mexeucomumamexeucomtodas é decorrente das mudanças comportamentais provocadas nas mulheres pelo advento da Aids, como o protagonismo da solidariedade que põe em segundo plano a liberdade sexual. Para defendê-la, arrola o seguinte evento: a crítica feita pelas francesas, liderada por Catherine Deneuve, ao movimento \#MeToo liderado pelas americanas. Ressaltamos aqui que, para defender essa posição, a autora traz fatos.

E, dentro da questão posta nesse debate, ela não "demoniza” o jogo da sedução, mas também defende o movimento americano que, comprovadamente, destituiu o produtor cinematográfico norte-americano de seu "trono".

Outra tese ainda defendida pela autora é a de que em "seu tempo" namoro entre mulheres era raro, diferente da experimentação existente nos dias de hoje. O raciocínio utilizado aqui é apenas indutivo, pois a autora se serve de sua observação pessoal: "Nos meus tempos de ginásio e científico", o que, para Othon, pode ser falacioso por ser apenas um indício e não evidência.

$\mathrm{Na}$ seção de comentários, o leitor A imediatamente retruca a informação sobre a ideia de que relações sexuais entre mulheres não constituiriam risco de contaminação da AIDS, construindo uma forte contra-argumentação, uma vez que se apoia numa afirmação científica e ataca a fragilidade do argumento da autora, a falácia (falsa causa) construída por ela.

Já o leitor B ataca a fragilidade do argumento explicando sua versão do debate entre francesas e americanas e, ainda, apontando que outros dados como lesbianismo, AIDS e sororidade nada têm a ver com a questão.

$\mathrm{O}$ leitor $\mathrm{C}$ se diferencia dos demais, uma vez que aceita os fatos, mas demonstra que foram mal empregados. Destaca outra perspectiva do mesmo fato, refutando a crítica feita pela autora no caso da afirmação de que Harvey Weinstein destruiu carreiras. $\mathrm{Na}$ concepção do referido leitor, o produtor teria ajudado a edificar carreiras com o consentimento das atrizes. 
A segunda crônica, de Gregório Duvivier (Anexo 2), A direita de facebook é ridicula, a esquerda é insuportável, defende, como sugere o título, que o debate entre esquerda e direita no facebook é ridículo. Para isso, enumera algumas "falas" de um lado e de outro, comprovando por fatos sua tese.

Um forte argumento empregado pelo autor é o de que, dessa forma, esvazia-se nossa indignação com a realidade circundante: governo, impostos, leis, fascismo. Ninguém percebe que os inimigos são os mesmos. Para elucidar a proposição, Duvivier utiliza um dos cinco tipos de evidência elencadas por Othon: a ilustração.

Por fim, termina sustentando a ideia de que nunca pediu nada a ninguém, muito menos que representa alguém. Aqui, o articulista responde a inúmeros comentários falaciosos em suas crônicas que se resumem em afirmar que ele não os representa.

$\mathrm{Na}$ seção de comentários, o leitor A ataca um ponto frágil de sua argumentação, concordando que ele traz uma "meia-verdade", visto que, no caso de Chico Buarque, a análise não se aplicaria, confirmando a tese de Othon de que muitas ideias admitem concordância parcial ou contestação parcial.

O leitor $\mathrm{B}$ já discorda inteiramente do posicionamento do articulista nessa questão e questiona a validade das ações de Boulos, Paula Lavigne, Emicida, Criolo, Chico Buarque e Jean Wyllys, com uma crítica pautada de ironia, no entanto não valida sua tese e seus argumentos.

Já outros comentários em grande número são apenas falaciosos, indicando ausência de um diálogo entre autor e leitor. São permeadas de falsos axiomas, observações inexatas, erros de acidente, ignorância da questão,... Em outros casos, limitam-se a atacar o cronista.

A terceira crônica, de Jânio de Freitas (Anexo 3), usa o incêndio do museu como símbolo do declínio do percurso previsto pela Constituição. Contesta a matéria do New York Times de que a perda do museu estaria ligada ao declínio de uma nação.

Para o articulista, apenas esboçamos traços de democracia (sua tese) e, para isso, utiliza fatos como a redução de algumas desigualdades e a denúncia de alguns dos muitos preconceitos. Ao mesmo tempo, explica de onde surge a impressão de declínio: judiciário, congresso e executivo frágeis. Critica o primeiro que, junto ao ministério público, deveria defender a Constituição e não aceitar abusos de poder e outras ilegalidades manifestados tanto por um candidato à presidência, quanto pela operação Lava Jato, provas evidentes para o articulista. 
Ataca novamente a justiça (TSE) com o exemplo do episódio em que descumpriu um acordo internacional, desqualificando o comitê internacional da ONU no caso da candidatura do ex-presidente Lula. Destaca que apenas um integrante do TSE foi capaz de se posicionar favoravelmente ao compromisso assumido.

$\mathrm{O}$ articulista fundamenta seu posicionamento com consistência de raciocínio e o evidencia com fatos: quadrilhas organizadas, falta de emprego, ausência de poderes oficiais e privados leais às suas responsabilidades,...

Sua conclusão não se reduz a recapitular apenas, mas pôr em termos mais claros a essência de sua proposição: "Os poderes compostos para orientar a construção da democracia, como pretendida pela Constituição, traem a ordem democrática.”

O leitor A responde com ironia e traz elementos novos que não contestam nenhuma das proposições, apenas revelam ausência de argumentos, já o leitor B concorda com a proposição e a complementa.

O leitor C, ao citar o vocábulo "fake" ao lado de democracia contesta uma das argumentações do articulista de que nossa democracia estaria sendo construída. Para ele, isso não é verdadeiro; contudo não desenvolve sua contra-argumentação.

O leitor D traz uma falácia, não ataca fatos, nem exemplos, apenas o próprio articulista: "Jânio é o exemplo mais perfeito da decadência moral, da completa inversão de valores."

$\mathrm{O}$ leitor $\mathrm{E}$ ataca um ponto fraco na argumentação do articulista, trazendo um dado novo, o fato de que não houve unanimidade no comitê da ONU também. E este mesmo leitor contesta também o seguinte ponto da argumentação: "com a redução de algumas desigualdades no governo Lula". Para isso, traz dados da pesquisa Unicef de 2015, segundo a qual 60\% das crianças ainda vivem na pobreza, o que não chega a ser suficiente para desqualificar a argumentação que não citou dados nem afirmou que o governo petista teria resolvido esse problema. Apesar de atacar pontos da argumentação, o leitor não chega a construir uma contra-argumentação sólida, uma vez que não há dados para comparação. 


\section{Considerações Finais}

Neste trabalho, apresentamos uma reflexão e uma retrospectiva do trabalho de Othon M. Garcia, uma “cartilha” para o iniciante em estudos de argumentação. Assim, discorremos sobre a importância da argumentação para a construção da nossa própria democracia e sobre os diversos recursos para formulação e refutação de argumentos.

Nosso intuito era verificar a qualidade do diálogo em rede, especificamente num segmento da sociedade considerado esclarecido, letrado, crítico, pois só é permitido fazer comentários aos assinantes do jornal, o que nos levou a inferir que este pertencesse a uma classe social mais privilegiada e escolarizada. Para nossa surpresa, a qualidade desses argumentos acabou por apontar a necessidade ainda maior de a escola recrudescer o trabalho com as estratégias de argumentação.

Muitos outros diálogos entre cronista e leitor foram excluídos aqui, propositadamente, pois só apresentavam ataques à pessoa do articulista e não à tese por ele defendida, o que descaracteriza uma argumentação consistente.

Não possuíamos expectativas, a priori, de que as condições de fala democrática fossem concretizar-se nos comentários aos artigos dos jornais. Pretendíamos, sim, explorar a elaboração da argumentação motivada pelo entendimento de que a web, sistema que configura um espaço por princípio democrático, contribuiria para a construção de uma verdadeira interação, de uma genuína influência recíproca, ou seja, favoreceria um diálogo de fato. 


\section{Referências}

BERNARDO, Gustavo. Redação Inquieta. 3a edição. Rio de Janeiro: Globo, 1988. 188 páginas.

CASTELLS, Manuel. A Galáxia da Internet: reflexões sobre a internet, os negócios e a sociedade. Rio de Janeiro: Zahar, 2003 (Trad. Maria Luiza X. de A. Borges)

RECUERO, R. Redes sociais na internet. Porto Alegre: Sulina, 2009. 191 p.

GARCIA, Othon M. Comunicação em prosa moderna. 27. ed. Rio de Janeiro: Ed. da FGV, 2010 